\title{
Effect of adding fat to the diet for lambs on the fatty acid profile of intramuscular, perirenal and subcutaneous fat
}

\author{
M. Szumacher-Strabel ${ }^{1,3}$, A. Potkański ${ }^{1}$, A. Cieślak ${ }^{1}$, J. Kowalczyk ${ }^{2}$ \\ and M. Czauderna ${ }^{2}$ \\ ${ }^{1}$ August Cieszkowski Agricultural University, \\ Department of Animal Nutrition and Feed Management \\ Wotyńska 33, 60-637 Poznań, Poland \\ ${ }^{2}$ The Kielanowski Institute of Animal Physiology and Nutrition, Polish Academy of Sciences \\ 05-110 Jabłonna, Poland
}

\begin{abstract}
The aim of the experiment was to determine the effect of rapeseed, soyabean, linseed, and fish oil as sources of polyunsaturated fatty acids in lamb diets on the fatty acid composition of intramuscular, subcutaneous and perirenal fat. Thirty fattened lambs of an average body weight of $22 \pm 3 \mathrm{~kg}$ were divided into five groups and fed a control diet without added oil, or experimental diets supplemented with $4 \%$ of a given oil. Linseed oil reduced $(P \leq 0.01)$ the ratio of $n-6$ to $n-3$ polyunsaturated fatty acids to the desired value, whereas both soyabean or fish oil raised $(\mathrm{P} \leq 0.01)$ this ratio in intramuscular fat. Linseed oil increased $(\mathrm{P} \leq 0.05)$, but rapeseed and fish oil decreased the level of monounsaturated fatty acids in perirenal fat. None of the oils affected the fatty acid concentration in subcutaneous fat. All supplemented oils increased $(\mathrm{P} \leq 0.05)$ intramuscular CLA. The highest was from $28.8 \mu \mathrm{g} / \mathrm{g}$ fat in control group to 33.3, 48.2, 53.4 and 97.1, respectively, with rapeseed oil, soyabean oil, linseed oil and fish oil addition. An increased CLA concentration in perirenal and subcutaneous fat was observed when linseed oil was added to the diets.
\end{abstract}

KEY WORDS: fatty acids, conjugated fatty acids, fat, oil, sheep

\section{INTRODUCTION}

The fatty acid profile of body lipids can be modified with most lipid sources in the diet, but not to a large extent (Doreau and Chilliard, 1997). According to Mir et al. (2002) supplementing diets for cattle with oils could be applied to alter

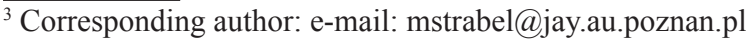


the fatty acid profile of adipose but not of intramuscular fat. Dietary vegetable oil supplementation could be used to substantially increase the conjugated linoleic acid (CLA) content of muscle fat. Beaulieu et al. (2002) suggested that supplementinghigh-concentrate finishing diets with soyabean oil or other sources of linoleic acid is not an efficacious method for increasing the CLA cis 9,trans 11 isomer in tissues. The conjugated linoleic acid content of tissues is higher in ruminants compared with non-ruminants, and among ruminants, lamb tissues are characterized as having the highest level of CLA. Mir et al. (2002) demonstrated that the CLA content in lamb muscle is altered by oil supplemented to the diet.

Given the increasing demand for meat and meat products rich in polyunsaturated fatty acids, including CLA, the objective of the experiment was to determine the effect of different oils as sources of polyunsaturated fatty acids on the fatty acid composition in lamb meat.

\section{MATERIAL AND METHODS}

Thirty fattened lambs of $22 \pm 3 \mathrm{~kg}$ body weight were divided into five groups and fed ad libitum meadow hay and concentrate without added oil as controls, or with the addition of $4 \%$ rapeseed oil (RSO) as a source of $\mathrm{C} 18: 1$, soyabean oil (SBO) as a source of C18:2, linseed oil (LSO) as a source of C18:3, or fish oil (FO) as a source of long-chain polyunsaturated fatty acids. The concentrate consisted of, \%: wheat meal, 60; rapeseed oilmeal, 18; mineral mixture, 2; and wheat bran, 20 in the control diet. The composition of experimental diets was as follows: wheat meal, 60; rapeseed oilmeal, 18; mineral mixture, 2; and wheat bran, 16; oil supplement, 4 .

Total fatty acid content and composition of intramuscular (IT), perirenal (PR) and subcutaneous (SC) fats were determined according to procedures of Czauderna et al. (2001). All data were analysed using SAS procedures (User's Guide, 1990).

\section{RESULTS}

Only few effects of the added oils on the fatty acid composition of lamb fat were observed. Linseed oil reduced $(P \leq 0.01)$ the ratio of $n-6$ to $n-3$ polyunsaturated fatty acids to the desired level $(2,3: 1)$, whereas both soyabean and fish oils increased $(\mathrm{P} \leq 0.01)$ the ratio in intramuscular fat, respectively, to 7,0:1 and 9,3:1 (Table 1).

Linseed oil also increased $(\mathrm{P} \leq 0.05)$ the level of monounsaturated fatty acids in perirenal fat. Rapeseed and fish oils had a slight, but significant, effect on the MUFA level (Table 2). 
Table 1. Fatty acid concentrations in intramuscular fat, $\mathrm{mg} / \mathrm{g}$ fat

\begin{tabular}{lccccc}
\hline Fatty acids & Control & Rapeseed oil & Soyabean oil & Linseed oil & Fish oil \\
\hline SFA $^{1}$ & 36.4 & 33.1 & 31.3 & 32.2 & 27.4 \\
MUFA $^{2}$ & 52.3 & 55.0 & 61.1 & 56.9 & 64.3 \\
PUFA $^{3}$ & 11.3 & 11.9 & 7.7 & 10.9 & 8.3 \\
PUFA-3 & 1.5 & 2.1 & 1.0 & 3.3 & 0.8 \\
PUFA-6 & 9.8 & 9.8 & 6.7 & 7.6 & 7.5 \\
MUFA+PUFA & 63.6 & 67.0 & 68.7 & 67.8 & 72.6 \\
PUFA6:PUFA3 & $6.8: 1^{\mathrm{cb}}$ & $4.6: 1^{\mathrm{cb}}$ & $7.0: 1^{\mathrm{bb}}$ & $2.3: 1^{\mathrm{cc}}$ & $9.3: 1^{\mathrm{aa}}$ \\
CLA, $\mu$ g/g fat & $28.8^{\mathrm{BB}}$ & $33.3^{\mathrm{AA}}$ & $48.2^{\mathrm{AA}}$ & $53.4^{\mathrm{AA}}$ & $97.1^{\mathrm{AA}}$ \\
\hline
\end{tabular}

means labeled with the same letter are not significantly different ${ }^{\mathrm{a}, \mathrm{b}, \mathrm{c}}-\mathrm{P}<0.01$

${ }^{1}$ saturated fatty acid, ${ }^{2}$ monounsaturated fatty acid, ${ }^{3}$ polyunsaturated fatty acid

Table 2. Fatty acid concentrations in perirenal fat, $\mathrm{mg} / \mathrm{g}$ fat

\begin{tabular}{lccccc}
\hline Fatty acids & Control & Rapeseed oil & Soyabean oil & Linseed oil & Fish oil \\
\hline SFA $^{1}$ & 36.3 & 40.2 & 37.6 & 22.0 & 45.5 \\
MUFA $^{2}$ & $53.1^{\mathrm{AB}}$ & $46.3^{\mathrm{BB}}$ & $54.1^{\mathrm{AB}}$ & $72.4^{\mathrm{AA}}$ & $48.3^{\mathrm{BB}}$ \\
PUFA $^{3}$ & 10.6 & 13.5 & 8.3 & 5.6 & 6.2 \\
PUFA-3 $_{\text {PUFA -6 }}$ & 3.4 & 5.4 & 3.3 & 2.0 & 2.4 \\
MUFA+PUFA & 7.3 & 8.2 & 5.1 & 3.5 & 3.8 \\
PUFA6:PUFA3 & 63.7 & 59.8 & 62.4 & 78.0 & 54.5 \\
CLA, $\mu$ g/g fat & $2.2: 1$ & $1.6: 1$ & $1.5: 1$ & $1.7: 1$ & $1.6: 1$ \\
\hline
\end{tabular}

means labeled with the same letter are not significantly different. ${ }^{\mathrm{A}, \mathrm{B}}-\mathrm{P}<0.05$

$1,2,3$ - as in the Table 1

None of the oils effected the fatty acid composition of subcutaneous fat (Table $3)$. The CLA content in intramusular fat was affected $(\mathrm{P} \leq 0.05)$ in all experimental groups. Addition of $4 \%$ linseed oil into the diet increased $(\mathrm{P} \leq 0.05)$ the level of CLA in subcutaneous fat and perirenal fat when compared with the control group.

Table 3. Fatty acid concentrations in subcutaneous fat, $\mathrm{mg} / \mathrm{g}$ fat

\begin{tabular}{lccccc}
\hline Fatty acids & Control & Rapeseed oil & Soyabean oil & Linseed oil & Fish oil \\
\hline SFA $^{1}$ & 34.0 & 38.6 & 17.7 & 14.2 & 26.3 \\
MUFA $^{2}$ & 59.8 & 51.9 & 78.0 & 81.6 & 68.4 \\
PUFA $^{3}$ & 7.2 & 9.5 & 4.3 & 4.2 & 5.3 \\
PUFA-3 & 0.3 & 2.7 & 0.6 & 0.9 & 0.8 \\
PUFA-6 & 5.9 & 6.8 & 3.7 & 3.2 & 4.5 \\
MUFA+PUFA & 67.0 & 61.4 & 82.3 & 85.8 & 73.7 \\
PUFA6:PUFA3 & $4.6: 1$ & $2.5: 1$ & $4.9: 1$ & $3.4: 1$ & $5.6: 1$ \\
CLA, $\mu$ g/g fat & $94.1^{\mathrm{BB}}$ & $51.6^{\mathrm{BB}}$ & $102.4^{\mathrm{BB}}$ & $118.6^{\mathrm{AA}}$ & $85.5^{\mathrm{BB}}$ \\
\hline
\end{tabular}

$1,2,3$ - as in the Table 1 


\section{DISCUSSION}

Ruminant meat, particularly lamb meat, is a rich source of n-6 and n-3 PUFA, conjugated linoleic acid plays a favourable role in the prevention and reduction of major diseases of civilization in humans (Geay et al., 2001). Therefore, it is recommended to increase the level of the desired fatty acids in meat fat. Our results showed a slight but not significant decrease of the saturated fatty acid level when diets were supplemented with $4 \%$ of oils. Ponnampalam et al. (2000) suggested that particularly fish oil can have a positive effect on polyunsaturated fatty acids (mostly $\mathrm{n}-3$ ) in meat. However, we did not observe the expected increase in polyunsaturated fatty acid content, especially when fish oil was supplemented to lamb diets, but fish oil significantly increased the CLA level in intramuscular fat. Other oils, sources of $\mathrm{C} 18$ unsaturated fatty acids, did not affect the fatty acid profile but increased the CLA level. The results obtained in this study are similar to those of Mir et al. (2002), in which sunflower oil did not affect muscle fat content but increased $(\mathrm{P} \leq 0.01)$ the conjugated fatty acid concentration by about four-fold.

\section{CONCLUSIONS}

Inclusion of vegetable or fish oil to the diet for sheep increased the level of CLA in the fat of lambs but did not increase the polyunsaturated fatty acid level or decrease the saturated fatty acid level. There was a tendency toward a decreased n-6: n-3 ratio when linseed oil was added to the diet.

\section{REFERENCES}

Beaulieu A.D., Drackley J.K., Merchen N.R., 2002. Concentrations of conjugated linoleic acid (cis-9, trans-11-octadecadienoic acid) are not increased in tissue lipids of cattle fed a highconcentrate diet supplemented with soybean oil. J. Anim. Sci. 80, 847-861

Czauderna M., Kowalczyk J., 2001. Separation of some mono-, di- and triunsaturated fatty acids containing 18 carbon atoms by high-performance liquid chromatography and photodiode array detection. J. Chromatogr. B 760, 165-178

Doreau M., Chilliard Y., 1997. Digestion and metabolism of dietary fat in farm animals. Brit. J. Nutr. $78, \mathrm{~S} 15-\mathrm{S} 35$

Geay Y., Bauchart D., Hocquette J.-F., Culioli J., 2001. Effect of nutritional factors on biochemical, structural and metabolic characteristics of muscles in ruminants, consequences on dietetic value and sensorial qualities of meat. Reprod. Nutr. Develop. 41, 1-26

Mir P.S., Mir Z., Kuber P.S., Gaskins C.T., Martin E.L., Dodson M.V., Elias Calles J.A., Johnson K.A., Busboom J.R., Wood A.J., Pittenger G.J., Reeves J.J., 2002. Growth, carcass characteristics, muscle conjugated linoleic acid (CLA) content, and response intravenous glucose challenge in high percentage Wagyu, Wagyu x Limousin and Limousin steers fed sunflower oil containing diets. J. Anim. Sci. 80, 2996-3004

Ponnampalam E.N., Sinclair A.J., Egan A.R., Blakeley S.J., Li D., Leury B.J., 2000. Effect of dietary modification of muscle long-chain n-3 fatty acid on plasma insulin and lipid metabolites, carcass traits, and fat deposition in lambs. J. Anim. Sci. 79, 895-903

SAS $^{\circledR}, 1990$. SAS/STAT Users Guide (Release 6.03). SAS Institute Inc., Cary, NC 